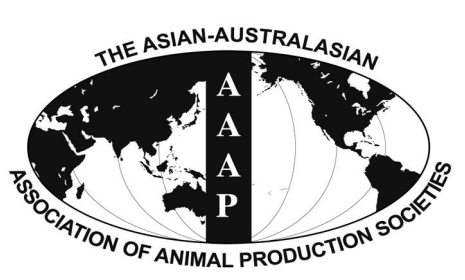

Open Access

Asian Australas. J. Anim. Sci.

Vol. 29, No. 9 : 1309-1313 September 2016

http://dx.doi.org/10.5713/ajas.15.0444

Www.ajas.info

pISSN 1011-2367 elSSN 1976-5517

\title{
Effects of Dietary Glucose on Serum Estrogen Levels and Onset of Puberty in Gilts
}

\author{
Fangfang Li, Yujing Zhu, Lan Ding, and Yong Zhang* \\ Department of Animal Nutrition, Faculty of Animal Sciences and Veterinary, \\ Shenyang Agricultural University, Shenyang 110866, China
}

\begin{abstract}
Metabolic signals and the state of energy reserves have been shown to play a crucial role in the regulation of reproductive function. This study was carried out to investigate the effects of dietary glucose levels on puberty onset in gilts. Weightmatched, landrace gilts $(\mathrm{n}=36) 162 \pm 3$ days old, weighing about $71.05 \pm 4.53 \mathrm{~kg}$, were randomly assigned to 3 dietary treatment groups of 12 gilts each. The trial lasted until the onset of puberty. Gilts in each group were supplied with diets containing different levels of glucose as follows: i) starch group (SG) was free of glucose, contained 64\% corn derived starch; ii) low-dose group (LDG) contained $19.2 \%$ glucose and $44.8 \%$ corn derived starch; iii) high-dose group (HDG) contained $30 \%$ glucose and $30 \%$ corn derived starch. Results indicated: i) The growth performance of gilts were not affected by the addition of glucose, but the age of puberty onset was advanced significantly $(p<0.05)$; ii) Compared with the SG, the concentration of insulin significantly increased before puberty in HDG ( $<<0.05$ ); iii) There was no difference in serum progesterone $(\mathrm{P})$ levels amongst the different feed groups, however, levels of estradiol $\left(\mathrm{E}_{2}\right)$, luteinizing hormone, and follicle-stimulating hormone were significantly higher at puberty onset in $\operatorname{HDG}(\mathrm{p}<0.05)$. Overall, our findings indicate that glucose supplementation significantly advances puberty onset, which can have practical purposes for commercial breeding. (Key Words: Glucose, Gilt, Growth Performance, Age of Puberty, Estrogen)
\end{abstract}

\section{INTRODUCTION}

In recent years, the advancement of pubertal onset in gilts due to diet composition has received increased attention. Advancing pubertal onset by 30 days also advances the age of breeding, which saves feed and resources. When animals reach a certain stage, the sensitivity of hypothalamus to gonadal steroid hormones is reduced; this is coupled with increased synthesis and secretion of gonadotropin-releasing hormone (GnRH) (Fauser, 2003; Plant et al., 2004). As the sensitivity of pituitary and gonads to $\mathrm{GnRH}$ is elevated, increased secretion of luteinizing hormone (LH) and folliclestimulating hormone (FSH) then promotes the synthesis of progesterone $(\mathrm{P})$ and estradiol $\left(\mathrm{E}_{2}\right)$, resulting in the start of estrus (Jin and Yang, 2014).

\footnotetext{
* Corresponding Author: Yong Zhang. Tel: +86-13889113626, E-mail: syau2011@163.com Submitted May 20, 2015; Revised Sept. 23, 2015; Accepted Dec. 1, 2015
}

Insulin, a hormone involved in glucose signaling, can function on hypothalamus directly and transmit signals regarding energy metabolism, which thereby regulates breeding performance of the animals. In vitro, it has been identified that insulin can enhance hypothalamic $\mathrm{GnRH}$ activity and mRNA expression, through the early growth response-1 protein (DiVall et al., 2007). Additionally, in pituitary cells cultured in vitro, insulin can promote the release of LH and FSH. Lastly, insulin can act on the ovary to affect the development of follicle by promoting ovulation and reducing follicular atresia (Castellano et al., 2009). Carbohydrates, proteins, and fats are the major dietary energy sources (Zhou et al., 2010). Yet glucose (composing carbohydrates), above all, contributes to the secretion of serum insulin and is important for insulin signaling. In this way, the practice of using fats as energy, instead of carbohydrates, may decrease reproductive performance in lactating sows through the absence of the effect of insulin (Hansen et al., 2014).

Glucose molecules, by and large, are absorbed by 
intestinal epithelial cells to provide energy for animals, while excess glucose is stored as hepatic glycogen or converted to other storage forms. Diet energy sources are mainly starch and fat, however, the role of glucose as the third energy source has still only occasionally been reported. In this study, feeds supplemented with different levels of glucose, starch, and fat were utilized to investigate whether glucose supplementation in diets affects growth, the age of puberty onset, and the production of serum estrogen in gilts.

\section{MATERIALS AND METHODS}

\section{Diets and feed manufacture}

Feeds used were commercial-type corn-soybean meal diet formulated to meet nutritional requirements of growing gilts as recommended by the NRC (1998) and were provided by Liaoning Wellhope Agri-Tech Co., Ltd. Each group was fed with feeds consisting of the same energy level, but from different energy sources: i) starch group (SG) was free of glucose, contained $64 \%$ corn derived starch; ii) low-dose group (LDG) contained $19.2 \%$ glucose and $44.8 \%$ corn derived starch; iii) high-dose group (HDG) contained $30 \%$ glucose and $30 \%$ corn derived starch. The diet composition and nutrients level are shown in Table 1. Gilts were allowed access to feed and water ad libitum. The trial lasted 60 days until the onset of puberty.

\section{Gilt experiment}

The animal care and use protocol was reviewed and approved by the Animal Care and Use Committee, Shenyang Agricultural University. Thirty six Landrace gilts at age of $162 \pm 3$ days, weighing about $71.05 \pm 4.53 \mathrm{~kg}$, were randomly divided into four groups, with 12 animals in each group. After 3 days of feed adaptation, gilts were weighed. The animals were weighed again at the end of the trial. Average daily gain (ADG), average daily feed intake (ADFI), and feed/gain ratio (F/G) were recorded daily. As an endogenous indicator, AIA was used for determining nutrient digestibility. Five gilts of similar condition were selected from each group and about $200 \mathrm{~g}$ of fecal sample from gilt was collected at 06:00 to $08: 00$ am on day 57, 58, and 59 respectively, and $20 \mathrm{~mL} 10 \%$ tartaric acid solution was added to fecal samples to avoid ammonia volatilization. Each fecal sample was sealed and frozen for nutrient digestibility analysis. Blood samples were collected from the superior vena cava on the day prior to the feeding trial, and on day 8, day 20 (prepubescent) after feeding, and the day of puberty onset. After incubating at room temperature for $15 \mathrm{~min}$, blood samples were centrifuged at 2,000 rpm for 20 min to obtain serum.

Genital observation was used to identify puberty onset in gilts during the trial period. The gilts were observed from 8:00 to 10:00 am and 15:00 to 17:00 pm daily. Onset of
Table 1. Composition and nutrient level of the test diets (air dry basis)

\begin{tabular}{lccc}
\hline Items & $\mathrm{SG}^{1}$ & $\mathrm{LDG}^{2}$ & $\mathrm{HDG}^{3}$ \\
\hline Ingredients & & & \\
Corn (\%) & 64.41 & 42.63 & 28.11 \\
Soybean meal (\%) & 11.24 & 15.27 & 17.95 \\
Wheat middlings (\%) & 15.00 & 15.00 & 15.00 \\
DDGS (\%) & 5.00 & 5.00 & 5.00 \\
Limestone (\%) & 1.17 & 1.42 & 1.36 \\
Premix & 0.40 & 0.40 & 0.40 \\
Salt (\%) & 0.60 & 0.60 & 0.50 \\
Choline chloride 50\% & 0.10 & 0.10 & 0.10 \\
Calcium hydrogen phosphate (\%) & 2.08 & 1.58 & 1.58 \\
Glucose & 0.00 & 18.00 & 30.00 \\
Total (\%) & 100 & 100 & 100 \\
Nutrient levels & & & \\
CP (\%) & 14.00 & 14.00 & 14.00 \\
Degesitable energy (MJ/kg) & 14.89 & 14.91 & 14.92 \\
EE (\%) & 4.12 & 3.20 & 2.59 \\
Crude ash (\%) & 6.07 & 5.92 & 5.79 \\
C-fiber (\%) & 3.79 & 3.59 & 3.46 \\
Ca (\%) & 1.00 & 1.00 & 0.98 \\
TP (\%) & 0.76 & 0.65 & 0.62 \\
Lys & 0.97 & 0.97 & 0.97 \\
Met+Cys & 0.43 & 0.43 & 0.43 \\
\hline DDGS dill $\%$ (\%) & & & \\
\hline
\end{tabular}

DDGS, distillers dried grains with soluble elements; CP, crude protein; EE, ether extract; TP, total phosphorus.

${ }^{1}$ The starch group (SG) was free of glucose, but containing $64 \%$ corn derived starch.

${ }^{2}$ The low-dose group (LDG) containing $19.2 \%$ glucose and $44.8 \%$ corn derived starch.

${ }^{3}$ The high-dose group (HDG) containing 30\% glucose and 30\% corn derived starch.

${ }^{4}$ Provided per kg of diet: vitamin A, 240,000 IU; vitamin $B_{1}, 30 \mathrm{mg}$; vitamin $\mathrm{B}_{2}, 120 \mathrm{mg}$; vitamin $\mathrm{B}_{6}, 60 \mathrm{mg}$; vitamin $\mathrm{B}_{12}, 360 \mathrm{mg}$; vitamin $\mathrm{D}_{3}, 60,000 \mathrm{IU}$; vitamin E, $720 \mathrm{IU}$; vitamin $\mathrm{K}_{3}, 30 \mathrm{mg}$; biotin, $0.1 \mathrm{mg}$; folic acid, $6 \mathrm{mg}$; D-pantothenic acid, $300 \mathrm{mg}$; nicotinic acid, $600 \mathrm{mg} ; \mathrm{Cu}$ (copper sulfate), $4 \mathrm{~g}$; $\mathrm{Fe}$ (as ferrous sulfate), $4 \mathrm{~g}$; Mn (manganese sulfate), $1.0 \mathrm{~g}$; Zn (zinc sulfate), $2.5 \mathrm{~g}$; I (potassium iodide), $2 \mathrm{mg}, \mathrm{Ca}$ (calcium), $150 \mathrm{~g}$, Se (sodium selenite), $6 \mathrm{mg}$; P (phosphorus), $300 \mathrm{~g}$; sodium chloride $48 \mathrm{~g}$.

${ }^{5} \mathrm{DE}$ was a calculated value.

Other nutrient levels were measured values.

puberty and time of standing heat were determined by an experienced stockperson based on behavioral and vulval characteristics. Behaviorally, standing still under applied back pressure was used as criterion to establish onset of estrus.

ADG, ADFI, and F/G were determined and used as parameters of growth performance. Blood glucose was tested using a kit purchased from Beijing Beihuan Kangtai Clinical Reagents Co., Ltd. Insulin, glucagon, $\mathrm{E}_{2}$, and $\mathrm{P}$ were detected by the Beijing Biotechnology Institute. Nutrient utilization was determined using the acid insoluble ash (AIA) endogenous indicator. The content of AIA in fecal samples was determined and the apparent digestibility 
of crude protein and crude fat was calculated.

\section{Statistics analyses}

The SPSS 14.0 software was used to determine the significance of the experimental data and the least significant difference method was used for multiple comparisons. Difference significance was taken at $\mathrm{p}<0.05$. Results are expressed as mean \pm standard deviation (SD).

\section{RESULTS}

As shown in Table 2, the ADG in glucose supplemented groups has no different with other groups ( $p>0.05)$. In LDG, the ADG was $12.7 \%$ higher than the $\mathrm{SG}(\mathrm{p}<0.05)$. The difference of feed conversion between groups was not significant $(\mathrm{p}>0.05)$.

There was no significant difference in apparent protein digestibility between groups $(p>0.05)$, the digestibility of nitrogen free extract (NFE) and the apparent digestibility of crude fat were not significant different amongst the groups ( $>0.05)$ (Table 3).

Puberty onset of gilts in LDG was significantly advanced compared to glucose free groups $(p<0.05)$. Notably, puberty onset in the HDG was 26 days earlier compared to the SG, and 19 days earlier compared to the LDG (Table 4) $(p<0.01)$. Significant changes in the body weight of pubertal gilts was not observed $(p>0.05)$.

Table 5 shows that serum glucose concentration in glucose supplemented groups did not increase. The insulin level of gilts in HDG was extremely elevated compared to the other groups before puberty $(\mathrm{p}<0.05)$. However, no difference was observed among groups at the onset of puberty $(\mathrm{p}>0.05)$. Serum $\mathrm{P}$ and glucagon concentrations of gilts were not affected $(p>0.05)$. The $E_{2}, L H$, and FSH concentration in HDG was significantly higher than in other groups at the onset of puberty $(\mathrm{p}<0.05)$, but no differences were discovered before puberty $(\mathrm{p}>0.05)$.
Table 2. Effects of glucose on growth of gilts

\begin{tabular}{lcccc}
\hline Items & SG & LDG & HDG & p value \\
\hline $\begin{array}{l}\text { Initial weight } \\
(\mathrm{kg})\end{array}$ & $70.26 \pm 2.93$ & $67.22 \pm 3.29$ & $71.27 \pm 2.53$ & 0.44 \\
Final weight $(\mathrm{kg})$ & $83.22 \pm 2.53$ & $79.00 \pm 3.63$ & $82.99 \pm 2.04$ & 0.25 \\
ADG $(\mathrm{kg})$ & $0.57 \pm 0.10$ & $0.51 \pm 0.03$ & $0.53 \pm 0.05$ & 0.71 \\
$\mathrm{ADFI}(\mathrm{kg})$ & $1.96 \pm 0.21^{\mathrm{a}}$ & $2.21 \pm 0.14^{\mathrm{c}}$ & $2.05 \pm 0.31^{\mathrm{b}}$ & 0.00 \\
F/G & $3.82 \pm 0.43$ & $4.47 \pm 0.24$ & $4.21 \pm 0.39$ & 0.54 \\
\hline
\end{tabular}

SG, starch group; LDG, low-dose group; HDG, high-dose group; ADG, average daily gain; $\mathrm{ADFI}$, average daily feed intake; F/G, feed/gain ratio. In the same row, values with different superscripts differ $(p<0.05)$.

\section{DISCUSSION}

Palatability is a major factor affecting feed intake and it has been suggested that glucose addition can improve feed palatability. However, feed intake levels of the HDG (containing 30\% glucose) declined compared to other groups, indicating that an optimal range of glucose addition may exist. Additionally, body weight gain of animals in the glucose supplemented groups was less than the SG In contrast, the feed conversion ratio acted oppositely, the feed conversion in SG was the lowest, followed by HDG, and LDG. The apparent ability of gilts to digest their diet was not significantly different. This is likely due to the fact that the digestive system of gilts is fully developed at the age of 160 days, resulting in complete digestion of the NFE and fat (Gerrits et al., 2001; Li et al., 2012).

The mammalian reproductive cycle is controlled by the complex interactions of hormones secreted by hypothalamus, pituitary, and gonads. In this study, puberty onset in animals receiving high glucose feed was significantly advanced compared with the other feed composition groups. It has been previously shown that glucose-induced insulin secretion leads to the GnRH secretion from the hypothalamus, increasing LH and FSH secretion and follicular development, thereby affecting pituitary and ovarian function (Jin and Yang, 2014). In a

Table 3. Effects of glucose on digestion

\begin{tabular}{llllc}
\hline Items & \multicolumn{1}{c}{ SG } & LDG & HDG & p value \\
\hline AIA (\%) & $11.05 \pm 0.43$ & $10.94 \pm 0.35$ & $10.64 \pm 0.76$ & 0.67 \\
CP apparent digestibility (\%) & $74.08 \pm 0.14$ & $75.81 \pm 0.93$ & $78.50 \pm 0.21$ & 0.96 \\
NFE digestibility (\%) & $88.6 \pm 0.68$ & $88.2 \pm 0.42$ & $87.9 \pm 0.59$ & 0.58 \\
EE apparent digestibility (\%) & $91.2 \pm 0.94$ & $90.9 \pm 0.28$ & $87.8 \pm 0.84$ & 0.51 \\
\hline
\end{tabular}

SG, starch group; LDG, low-dose group; HDG, high-dose group; AIA, acid insoluble ash; CP, crude protein; NFE, nitrogen free extract; EE, ether extract. In the same row, values with different superscripts differ $(\mathrm{p}<0.05)$.

Table 4. Effects on the advent of puberty and body weight of gilts after glucose supplementation

\begin{tabular}{lcccc}
\hline Items & SG & LDG & HDG & p value \\
\hline Age of puberty $(\mathrm{d})$ & $222.51 \pm 4.89^{\mathrm{b}}$ & $215.80 \pm 3.52^{\mathrm{b}}$ & $196.42 \pm 1.84^{\mathrm{a}}$ & 0.00 \\
Body weight at onset of puberty $(\mathrm{kg})$ & $98.84 \pm 2.65$ & $95.41 \pm 3.56$ & $102.44 \pm 4.63$ & 0.54 \\
\hline
\end{tabular}

SG, starch group; LDG, low-dose group; HDG, high-dose group.

In the same row, values with different superscripts differ $(\mathrm{p}<0.05)$. 
Table 5. Serum parameters of gilts of different ages after glucose supplementation

\begin{tabular}{llcccc}
\hline Items & \multicolumn{1}{c}{ Age } & SG & LDG & HDG & p value \\
\hline Glucose $(\mathrm{mmol} / \mathrm{L})$ & Beforre puberty & $5.93 \pm 0.27$ & $5.42 \pm 0.22$ & $5.38 \pm 0.34$ & 0.57 \\
& Puberty & $5.77 \pm 0.20$ & $5.53 \pm 0.39$ & $5.51 \pm 0.31$ & 0.06 \\
Insulin $(\mu \mathrm{IU} / \mathrm{mL})$ & Before puberty & $6.10 \pm 1.99^{\mathrm{a}}$ & $10.33 \pm 2.02^{\mathrm{b}}$ & $28.66 \pm 1.67^{\mathrm{c}}$ & 0.01 \\
& Puberty & $13.78 \pm 1.55$ & $12.15 \pm 1.91$ & $14.59 \pm 1.49$ & 0.59 \\
Glucagon $(\mathrm{pg} / \mathrm{mL})$ & Before puberty & $155.25 \pm 5.74$ & $132.75 \pm 10.22$ & $146.48 \pm 16.72$ & 0.53 \\
& Puberty & $161.89 \pm 13.8$ & $155.23 \pm 10.2$ & $164.30 \pm 10.80$ & 0.83 \\
$\mathrm{E}_{2}(\mathrm{pg} / \mathrm{mL})$ & Before puberty & $13.55 \pm 1.83$ & $16.91 \pm 1.56$ & $18.59 \pm 1.15$ & 0.56 \\
& Puberty & $25.66 \pm 1.52^{\mathrm{a}}$ & $27.78 \pm 2.31^{\mathrm{a}}$ & $33.62 \pm 2.43^{\mathrm{b}}$ & 0.02 \\
$\mathrm{P}(\mathrm{pg} / \mathrm{mL})$ & Before puberty & $10.34 \pm 0.17$ & $9.95 \pm 0.15$ & $10.79 \pm 0.80$ & 0.71 \\
& Puberty & $13.31 \pm 0.12$ & $24.04 \pm 0.27$ & $13.24 \pm 0.56$ & 0.08 \\
$\mathrm{LH}(\mathrm{ng} / \mathrm{mL})$ & Before puberty & $0.21 \pm 0.03$ & $0.23 \pm 0.02$ & $0.23 \pm 0.04$ & 0.91 \\
& Puberty & $1.55 \pm 0.32^{\mathrm{a}}$ & $1.61 \pm 0.30^{\mathrm{a}}$ & $1.83 \pm 0.26^{\mathrm{b}}$ & 0.04 \\
FSH $(\mathrm{ng} / \mathrm{mL})$ & Before puberty & $1.86 \pm 0.25$ & $1.83 \pm 0.14$ & $1.93 \pm 0.30$ & 0.87 \\
& Puberty & $2.10 \pm 0.41^{\mathrm{a}}$ & $2.20 \pm 0.36^{\mathrm{a}}$ & $2.61 \pm 0.39^{\mathrm{b}}$ & 0.02 \\
\hline
\end{tabular}

SG, starch group; LDG, low-dose group; HDG, high-dose group; $\mathrm{E}_{2}$, estradiol; P, progesterone; LH, luteinizing hormone; FSH, follicle-stimulating hormone.

In the same row, values with different superscripts $\operatorname{differ}(\mathrm{p}<0.05)$

previous study conducted in SD rats, diet supplementation with multivitamin-glucose was added to diets, vaginal opening (an external marker of puberty onset in rodents) occurred earlier, indicating that glucose addition advanced puberty onset in rats (Fan et al., 1997; Matsui et al., 2004), which is similar to our findings in the pig.

The addition of dietary glucose did not affect the levels of serum glucose. This is likely due to the fact that glucose can induce the secretion of insulin and pancreatic glucagon to regulate blood glucose levels within a stable range. This is similar to findings in rats, where it was shown that highglucose and high-fat diets have no effect on the blood glucose levels (Steger and Rabe, 1997). Glucose and insulin play an important role in the reproductive function of prepubertal gilts (Kemp et al., 1995). Kapelanski et al. (2008) suggested that providing an insulin-promoting diet, via glucose supplementation for sows, was a means of stimulating sexual maturity and inducing insulin cycling. The reports mentioned above are very consistent with our current findings in gilts. Insulin as peripheral nutrition signal, not only affects the hypothalamic - pituitary gonadal axis, but also signals into the reproductive axis via insulin-like growth factor (IGF), growth hormone (Kemp et al., 1995). At present, there are many theories on the relationship between insulin, and other insulin-like factors in regulating reproduction, but much of the data is contradictory and further studies will need to be performed in order to tease apart these relationships. Additionally, studies investigating the optimal levels and timing of glucose supplementation for estrus induction will also be important to conduct.

Our results indicated that serum $\mathrm{E}_{2}, \mathrm{LH}$, and FSH concentrations were significantly higher upon with glucose supplementation. Previous studies have indicated that IGF-1 can act on ovarian granulosa cells and endometrial cells to produce androgen, which is converted into estrogen via aromatase (Jin and Yang, 2014). A high concentration of $E_{2}$ in pubertal gilts is essential for the start of estrus. When gilts got puberty onset, GnRH secretion increased, followed by the secretion of LH and FSH for the start of estrus (Jin and Yang, 2014). P concentrations were lower in adolescent animals, even though the concentration of $E_{2}$ increased before the start of estrus, and $\mathrm{P}$ content was maintained at low levels (Irwig et al., 2005; Zhou et al., 2014). After uterus, $E_{2}$ levels decreased, while concentration of $P$ began to rise.

\section{IMPLICATIONS}

In conclusion, current study demonstrated that growth performance of gilts supplemented with glucose in feed was unaffected, but their ADFI improved. Glucose supplementation also significantly advanced puberty onset, significantly increased serum insulin concentrations, slightly affected serum $E_{2}$ concentrations, but had no significant effects on nutrient digestibility, and body weight gain. Appropriate supplementation of glucose in diet can promote the reproductive performance of gilts and have practical uses for breeding.

\section{CONFLICT OF INTEREST}

We certify that there is no conflict of interest with any financial organization regarding the material discussed in the manuscript. 


\section{ACKNOWLEDGMENTS}

The work was supported by the funding of Chinese NSFC, grant Nos. 31440082 and 31101253.

\section{REFERENCES}

Castellano, J. M., V. M. Navarro, J. Roa, R. Pineda, M. A. Sanchez-Garrido, D. Garcia-Galiano, E. Vigo, C. Dieguez, E. Aguilar, L. Pinilla, and M. Tena-Sempere. 2009. Alterations in hypothalamic KiSS-1 system in experimental diabetes: Early changes and functional consequences. Endocrinology 150:784794.

DiVall, S. A., S. Radovick, and A. Wolfe. 2007. Egr-1 binds the GnRH promoter to mediate the increase in gene expression by insulin. Mol. Cell Endocrinol. 270:64-72.

Fan, B., X. Sun, J. Wang, and X. Zhang. 1997. Effect of dietary energy restriction on reproduction in rats. Wei Sheng Yan Jiu. 26:327-329 (Article in Chinese).

Gerrits, W. J. J., M. J. W. Heetkamp, T. Zandstra, and J. W. Schrama. 2001. Effect of synchronizing dietary protein and glucose supply on nitrogen retention in growing pigs. J. Anim. Sci. 79:S3-S6.

Hansen, A. V., A. B. Strathe, P. K. Theil, and E. Kebreab. 2014. Energy and nutrient deposition and excretion in the reproducing sow: model development and evaluation. J. Anim. Sci. 92:2458-2472.

Irwig, M. S., G. S. Fraley, J. T. Smith, B. V. Acohido, S. M. Popa, M. J. Cunningham, M. L. Gottsch, D. K. Clifton, and R. A. Steiner. 2005. Kisspeptin activation of gonadotropin releasing hormone neurons and regulation of KiSS-1 mRNA in the male rat. Neuroendocrinology 80:264-272.

Jin, J. M. and W. X. Yang. 2014. Molecular regulation of hypothalamus-pituitary-gonads axis in males. Gene 551:15-25.
Kapelanski, W., M. Biegniewska, and H. Jankowiak. 2008. Results of sow reproductive performance due to application of insulingenic diet and natural stimulation of estrus. Res. Pig Breed. 2:19-21.

Kemp, B., N. M. Soede, F. A. Helmond, and M. W. Bosch. 1995. Effects of energy source in the diet on reproductive hormones and insulin during lactation and subsequent estrus in multiparous sows. J. Anim. Sci. 73:3022-3029.

Li, X. F., Y. S. Lin, J. S. Kinsey-Jones, and K. T. O'Byrne. 2012. High-fat diet increases LH pulse frequency and kisspeptinneurokinin $\mathrm{B}$ expression in puberty-advanced female rats. Endocrinology 153:4422-4431.

Matsui, H., Y. Takatsu, S. Kumano, H. Matsumoto, and T. Ohtaki. 2004. Peripheral administration of metastin induces marked gonadotropin release and ovulation in the rat. Biochem. Biophys. Res. Commun. 320:383-388.

NRC (National Research Council). 1998. Nutrient Requirements for Swine, 10th edn. National Academy Press, Washington DC, USA.

Plant, T. M. and M. L. Barker-Gibb. 2004. Neurobiological mechanisms of puberty in higher primates. Hum. Reprod. Update 10:67-77.

Steger, R. W. and M. B. Rabe. 1997. The effect of diabetes mellitus on endocrine and reproductive function. Proc. Soc. Exp. Biol. Med. 214:1-11.

Fauser, B. C. J. M. 2003. Reproductive medicine: molecular, cellular and genetic fundamentals. J. Am. Med. Assoc. (JAMA). 290:3005-3005.

Zhou, D., Y. Zhuo, L. Che, Y. Lin, Z. Fang, and D. Wu. 2014. Nutrient restriction induces failure of reproductive function and molecular changes in hypothalamus-pituitary-gonadal axis in postpubertal gilts. Mol. Biol. Rep. 41:4733-4742.

Zhou, D. S., Z. F. Fang, D. Wu, Y. Zhuo, S. Y. Xu, Y. Z. Wang, P. Zhou, and Y. Lin. 2010. Dietary energy source and feeding levels during the rearing period affect ovarian follicular development and oocyte maturation in gilts. Theriogenology 74:202-211. 